\title{
Case report of a 45-year old female Fabry disease patient carrying two alpha- galactosidase A gene mutation alleles
}

\author{
Daniel Oder ${ }^{1,2}$, Dorothee Vergho ${ }^{1,2}$, Georg Ertt ${ }^{1,2}$, Christoph Wanner ${ }^{1,2}$ and Peter Nordbeck ${ }^{1,2^{*}}$
}

\begin{abstract}
Background: X-chromosomal inheritance patterns and generally rare occurrence of Fabry disease (FD) account for mono-mutational hemizygous male and heterozygous female patients. Female mutation carriers are usually clinically much less severely affected, which has been explained by a suggested mosaicism in cell phenotype due to random allele shutdown. However, clinical evidence is scarce and potential additional effects in female gene carriers, which might account for specific clinical characteristics such as less severe chronic kidney disease, are yet unknown.

Case presentation: This article reports on a 45 year old female patient carrying the two alpha-galactosidase $A$ gene mutations c.416A > G, p.N139S in exon 3 and c.708G > C, p.W236C in exon 5, but still showing only mild organ manifestations.

Conclusion: This current case highlights the importance of careful clinical characterization in patients with Fabry disease, who may show additional rare constellations and, therefore, are in need of personalized medicine. The impact of potential additional protective effects exceeding the presence of a non-pathogenic GLA allele in female gene carriers requires further investigation.
\end{abstract}

Keywords: Fabry disease, Cryptogenic stroke, Pain, Hypertrophic cardiomyopathy, Chronic kidney disease

\section{Background}

Anderson-Fabry disease (FD) is a rare, X-chromosomal inherited lysosomal storage disorder resulting from currently over 800 known pathogenic alpha-galactosidase $\mathrm{A}$ gene $(G L A)$ mutations $[1,2]$. Recent focus has been set on understanding mutation-specific clinical characteristics and outcome, which might eventually lead to a clinically relevant sub-classification of $\mathrm{FD}$, such as into classical, non-classical, "late onset" and/or organ-specific variants [3-6]. While most X-linked diseases only cause phenotypical manifestations in male patients with females usually being completely unaffected carriers $[7,8]$, FDfemales may develop manifestations to a specific extent, which are usually much less severe in terms of clinical

\footnotetext{
*Correspondence: nordbeck_p@ukw.de

'Department of Internal Medicine I and Comprehensive Heart Failure Center

(CHFC), University Hospital Würzburg, Oberdürrbacher Str. 6, D-97080

Würzburg, Germany

${ }^{2}$ Fabry Center for Interdisciplinary Therapy (FAZIT), University Hospital

Würzburg, Würzburg, Germany
}

symptoms compared to respective men $[2,9,10]$. This is attributed to the fact that women nearly always present a heterozygous GLA genotype including one further, nonpathologically affected allele. However, the definite underlying mechanisms ultimately leading to somewhat less morbidity in female FD patients are still under debate. A potential impact of skewed X-inactivation has been supposed central, leading to random transcriptional silencing of one of both X-chromosomes in every cell, eventually leading to the typical findings of female genetic mosaicism $[8,11,12]$. Due to the marked variance of FD regarding clinical symptoms, there is high interest to characterize the impact of genotypes in order to embrace patients individualized additive therapeutic needs aside from enzyme replacement therapy (ERT) and improve mechanistic knowledge regarding genotype-phenotype pathophysiology. 
Table 1 General- and Fabry-associated characteristics, biomarkers, renal function and quality of life of the index patient

\begin{tabular}{|c|c|c|}
\hline Variables & Index patient & Reference values \\
\hline \multicolumn{3}{|l|}{ Demographics } \\
\hline Age at first visit (years) & 44 & \\
\hline Body-mass-index (kg/m2) & 20.7 & \\
\hline \multicolumn{3}{|l|}{ Biomarkers } \\
\hline Lyso-Gb3 (ng/ml) & 30.2 & $<0.9$ \\
\hline a-Gal A (nmol/min/mg protein) & 0.26 & $0.4-1.0$ \\
\hline NT-proBNP (pg/ml) & 325 & $\begin{array}{l}0-153 \text { (age- } \\
\text { dependent) }\end{array}$ \\
\hline hs-TnT (pg/ml) & $<5$ & $0-14$ \\
\hline \multicolumn{3}{|l|}{ Renal } \\
\hline Serum-Creatinine (mg/dl) & 0.80 & $0-0.95$ \\
\hline Cystatin C (mg/l) & 0.76 & $0.61-0.95$ \\
\hline GFR DTPA Clearance (ml/min) & 90 & $90-150$ \\
\hline \multicolumn{3}{|l|}{ Fabry associated } \\
\hline Angiokeratoma & none & \\
\hline Cornea verticillata & yes & \\
\hline Impaired sweating & yes & \\
\hline Vertigo & yes & \\
\hline Tinnitus & yes & \\
\hline Frequent diarrhea & yes & \\
\hline Constipation & none & \\
\hline Abdominal pain & none & \\
\hline Abdominal cramps & none & \\
\hline Nausea/vomiting & none & \\
\hline \multicolumn{3}{|l|}{ Medication } \\
\hline ERT & $\begin{array}{l}\text { Agalsidase } \\
\text { beta }\end{array}$ & \\
\hline Beta blocker & none & \\
\hline ACEi/ARBs & none & \\
\hline Ca-blockers & none & \\
\hline Diuretics & none & \\
\hline ASA/OAC & yes & \\
\hline \multicolumn{3}{|l|}{ Quality of life (SF-36 questioner) } \\
\hline Physical functioning & 75 & \\
\hline Role physical & 0 & \\
\hline Bodily pain & 100 & \\
\hline General health & 45 & \\
\hline Vitality & 20 & \\
\hline Social functioning & 12.5 & \\
\hline
\end{tabular}

Table 1 General- and Fabry-associated characteristics, biomarkers, renal function and quality of life of the index patient (Continued)

\begin{tabular}{ll}
\hline Role emotional & 100 \\
Mental health & 48 \\
Physical component summary & 41.61 \\
score & \\
Mental component summary & 35.17 \\
score & \\
\hline Abbreviations: $a$-Gal Aalpha-galactosidase A enzyme activity, ACEi \\
angiotensin-converting-enzyme inhibitor, ARBs Angiotensin II receptor \\
antagonists, ASA/OAC acetylsalicylic acid/oral anticoagulation therapy, ERT \\
enzyme replacement therapy, GFR glomerular filtration rate, $h$ s-TnT \\
high-sensitive troponin T, NT-proBNP N-terminal pro-brain natriuretic peptide \\
Methods
\end{tabular}

All patients attending the Fabry Center for Interdisciplinary Therapy (FAZIT) Wurzburg, Germany, undergo a standardized comprehensive clinical, laboratory and imaging examination with special focus on Fabry-related impairments and organ involvement. Cardiac imaging modalities include standard twodimensional echocardiography, as well as speckle tracking analysis, and cardiac magnetic resonance tomography (MRI), both beneficial for indirect quantification of intramural fibrosis as prominently seen in advanced Fabry cardiomyopathy [13-15]. Investigations also include a thorough investigation of the kidneys including biopsy if suitable, central and peripheral nervous system including brain MRI, skin biopsy, and assessment of sweating capacity, and psychic factors, including assessment of quality of life using SF-36.

\section{Case presentation}

In late 2015, a 45-year-old female patient with genetically proven FD approached FAZIT for specialized clinical evaluation and therapy induction. Molecular gene analysis revealed the atypical situation of a heterozygous female patient carrying two different haplotype variants - c.416A > G, p.N139S in exon 3 and c.708G > C, p.W236C in exon 5, one on each Xchromosomal allele - which both have previously been described as potentially pathogenic [16, 17]. Due to the low frequency of pathogenic GLA mutations in the population, comparable respective cases are extremely rare. The initial suspicion for FD in this index patient was raised during a routine ophthalmologist checkup leading to the discovery of Fabryspecific depositions in her cornea at young age of six years. Later on, it was revealed that not only her mother, but also her brother are both affected by the same mutational variant (c.708G > C, p.W236C in exon 5), which was in both relatives clinically related to Fabryassociated acral pain, myocardial hypertrophy, and renal 
dysfunction. In addition, the index patient's brother suffered from young-aged stroke at age 45 years and now receives hemodialysis due to end-stage chronic kidney disease. Her grandfather from maternal site is anticipated to have been affected by FD, suffering from fatal end-stage kidney disease at his early forties. Unfortunately, the index patient's 74 years old father refused to undergo genetic analysis. As the index patient never subjectively suffered from any health problems, neither doctors were consulted nor medication taken until the event of young-aged cryptogenic stroke at the age of 44 years. As a result of stroke, she attended FAZIT for clinical examination and initiation of life-time ERT.

At FAZIT she denied any acral pain or gastrointestinal claims besides of frequent diarrhea. Sweating capacity was reported mildly reduced, but only attracted her attention in hot summer months (Table 1). Alphagalactosidase A ( $\alpha$-Gal $A)$ enzyme activity was measured reduced $(0.26 \mathrm{nmol} / \mathrm{min} / \mathrm{mg}$ protein in leucocytes; reference: $0.4-1.0)$ and plasma lyso-Gb3 was elevated (30.2 $\mathrm{ng} / \mathrm{ml}$; reference: $\leq 0.9$ ). The body-mass-index $\left(20.5 \mathrm{~kg} / \mathrm{m}^{2}\right)$, resting blood pressure $(100 / 82 \mathrm{mmHg})$ and heart rate $(80 \mathrm{bpm})$ were all in normal ranges, with sinus rhythm and no signs of cardiac hypertrophy or ischemia in neither resting, nor exercise electrocardiograms (ECG). (Table 2) Physical capacity in exercise ECG was sufficient, reaching a maximal heart rate of $133 \mathrm{bpm}, 75 \%$ of the age-predicted optimum of $176 \mathrm{bpm}$ at $125 \mathrm{~W}$. No spontaneous cardiac arrhythmia was detectable in Holter monitoring, or evocable in exercise stress test. The cardiac biomarker high-sensitive troponin $\mathrm{T}$ was inconspicuous for cardiac involvement $(<5 \mathrm{pg} / \mathrm{ml}$; reference: $0-14)$. $\mathrm{N}$-terminal pro-brain natriuretic peptide was slightly elevated $(325 \mathrm{pg} / \mathrm{ml}$; reference: <125), which might be a hint on an early stage cardiac involvement. This suspicion from blood biomarkers was supported by findings in standard cardiac imaging, revealing borderline septal and posterior wall thickness of $11 \mathrm{~mm}$ and a visually determined concentric left ventricular (LV) hypertrophy with prominent papillary muscles but physiologically preserved LV ejection fraction (68\%) in echocardiography. The normalized LV mass was $66.7 \mathrm{~g} / \mathrm{m}^{2}$, normalized end-systolic volume $26.0 \mathrm{ml} / \mathrm{m}^{2}$, normalized end-diastolic volume $75.9 \mathrm{ml} /$ $\mathrm{m}^{2}$, normalized stroke volume $49.9 \mathrm{ml} / \mathrm{m}^{2}$, and the cardiac index $3.19 \mathrm{l} / \mathrm{min} / \mathrm{m}^{2}$ in cardiac MRI with minimal intramural left ventricular late gadolinium enhancement, as seen in early stage Fabry cardiomyopathy (Fig. 1a/b) $[15,18]$. In order to more evidently investigate the possible presence of mild fibrotic scar tissue, twodimensional echo speckle tracking was performed, allowing inferences on myocardial muscle rigidity and stiffness in an 18 segment model. The result revealed a mild pathologic peak systolic strain in the posterior-
Table 2 Cardiac features and imaging modalities results in the index patient

\begin{tabular}{|c|c|}
\hline Variables & Index patient \\
\hline \multicolumn{2}{|l|}{ Cardio-vascular } \\
\hline Systolic blood pressure (mmHg) & 115 \\
\hline Diastolic blood pressure (mmHg) & 75 \\
\hline Heart rate (bpm) & 68 \\
\hline \multicolumn{2}{|l|}{ Cardiac stress test } \\
\hline maximal heart rate (bpm) & 133 \\
\hline maximal watts (watts) & 75 \\
\hline \multicolumn{2}{|l|}{ Echocardiography } \\
\hline LVEF (\%) & 68 \\
\hline IVSd (mm) & 11 \\
\hline LVPWd (mm) & 11 \\
\hline LVMI $\left(\mathrm{g} / \mathrm{m}^{2}\right)$ & 88 \\
\hline E/A & 1.3 \\
\hline$E / E^{\prime}$ & 10 \\
\hline $\mathrm{DT}(\mathrm{ms})$ & 155 \\
\hline \multicolumn{2}{|l|}{ Speckle tracking strain [\%] } \\
\hline global strain & -23.44 \\
\hline basal strain & -15.79 \\
\hline mid strain & -21.18 \\
\hline apical strain & -33.74 \\
\hline septal strain & -25.71 \\
\hline lateral strain & -21.43 \\
\hline \multicolumn{2}{|l|}{ Speckle tracking strain rate $\left[\mathrm{S}^{-1}\right]$} \\
\hline global strain rate & -1.50 \\
\hline basal strain rate & -1.24 \\
\hline mid strain rate & -1.25 \\
\hline apical strain rate & -2.17 \\
\hline septal strain rate & -1.61 \\
\hline lateral strain rate & -1.49 \\
\hline \multicolumn{2}{|l|}{ Cardiac MRI } \\
\hline LGE (yes/no) & none \\
\hline normalized LVM $\left(\mathrm{g} / \mathrm{m}^{2}\right)$ & 66.7 \\
\hline normalized ESV $\left(\mathrm{ml} / \mathrm{m}^{2}\right)$ & 26.0 \\
\hline normalized EDV $\left(\mathrm{ml} / \mathrm{m}^{2}\right)$ & 75.9 \\
\hline normalized SV $\left(\mathrm{ml} / \mathrm{m}^{2}\right)$ & 49.9 \\
\hline $\mathrm{Cl}\left(1 / \mathrm{min} / \mathrm{m}^{2}\right)$ & 3.19 \\
\hline LVEF (\%) & 65.7 \\
\hline
\end{tabular}

Abbreviations: DT deceleration time, IVSd interventricular septum thickness in end-diastole, $L V E F$ left ventricular ejection fraction in \%, LVMI left ventricular mass index in echocardiography, LVPWD left ventricular posterior wall thickness in end-diastole, normalized EDV normalized end-diastolic volume in cardiac MRI, normalized ESV normalized end-systolic volume in cardiac MRI, normalized LVM normalized left ventricular mass in cardiac MRI, normalized SV normalized stroke volume in cardiac MRI 

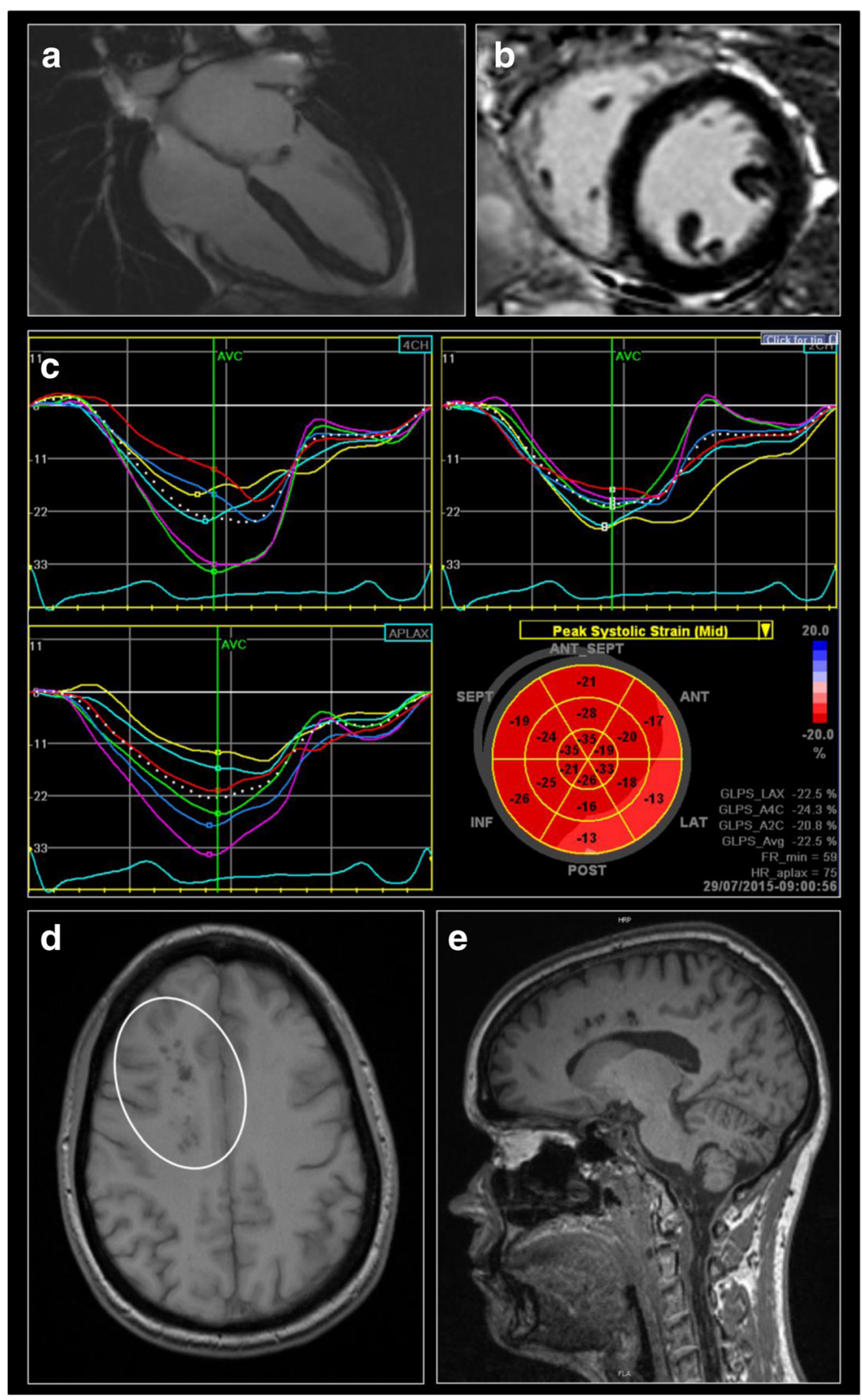

Fig. 1 Index patient's imaging features of cardiac a-c and brain $\mathbf{d}-\mathbf{e}$ involvement at FAZIT baseline visit. Please note that morphologic and late gadolinium enhancement cardiac MRl $\mathbf{a}-\mathbf{b}$ reveals mild hypertrophy and marginal fibrotic scar tissue with only minimal intramural late gadolinium enhancement detectable. In two-dimensional speckle tracking c peak systolic strain is mildly reduced, visualizing in loco typico early stage Fabry cardiomyopathy in the posterior-lateral and antero-lateral walls (bull's eye method). Brain MRI d-e shows residual lesions (encircled) due to previously suffered cryptogenic stroke

lateral and anterior-lateral wall segments visualized by speckle tracking bull's eye (Fig. 1c) hinting on a very early stage of cardiomyopathy [14]. Renal function was completely preserved, with a 99-Technetium DTPA clearance of $90 \mathrm{ml} / \mathrm{min}$, a serum-creatinine of $0.80 \mathrm{mg} / \mathrm{dl}$ (reference: 0-0.95), and cystatin-c of $0.76 \mathrm{mg} / \mathrm{l}$ (reference: 0.61-0.95), with no prove of pathologic proteinuria in spot or collecting urine. Brain MRI revealed residual lesions due to the previously suffered stroke (Fig. 1d/e), Health related quality of life was accessed by the SF-36 questionnaires and revealed reduced physical (41.61 out of $100)$ and mental component summary scores (35.17 out of 100) reflecting both somatic and mental impact on the index patient's subjective well-being.

By rules of genetic penetrance, in this particular case the index patient conducts one of her pathogenic GLA alleles to all of her biological descendants. Thus both of her children, an 11 year old daughter and her 8 year old son underwent genetic analysis for FD (Centogene AG, 
Rostock, Germany), both presenting the c.708G > C, p.W236C mutation in exon 5. $\alpha$-Gal A enzyme activity was reduced in her daughter $(0.20 \mathrm{nmol} / \mathrm{min} / \mathrm{mg}$ protein in leucocytes) and highly reduced in the index patient's son $(0.03 \mathrm{nmol} / \mathrm{min} / \mathrm{mg}$ protein in leucocytes). LysoGb3 was $8.1 \mathrm{ng} / \mathrm{ml}$ in the index patient's daughter and not determined in her son. Interestingly, her son already claims about stinging pain occurring in situations of bodily stress and during infections even though he is at very young age.

Female mutation carriers usually present milder phenotypes than comparable males, which might be explained due to compensatory effects of the second, nonpathologically affected allele. In rare cases of homozygous female patients classical FD is to be expected. In this regard, Rodríguez-Marí and colleagues reported about a young female patient, who was found homozygous for the Q279R GLA mutation and presented a classics Fabry-phenotype with cardiac and neurological organ involvement, reduced $\alpha$-Gal $A$ activity, Fabry-associated angiokeratoma, a reduced sweating capacity and acral pain, which started at young age of 8 years [19]. In contrast, all three female homozygous patients (p.Arg118Cys variant) published by Susana Ferreira and colleagues did not develop a classical Fabry phenotype, highlighting the impact of mutation-specific factors in FD [20]. However, contradictory to both mentioned reports, the index patient of the current study was found homozygous with not one and the same, but two different GLA mutations in each of her alleles. Regarding our index patient, family pedigree, laboratory data, and clinical manifestations give a mixed picture regarding disease patterns. While young-aged stroke gives evidence for neurological manifestations, further organ involvement was minimal with only very mild cardiac and no renal impairments detectable. Comparing her clinical course to her brothers', much less severe manifestations were found. This could indicate that there might not be an additive effect of two independent pathogenic GLA alleles, questioning the anticipated clinical impact of skewed $\mathrm{X}$-inactivation leading to silence of the index patient's second pathogenic allele. It might instead be speculated that there could be so far unknown additional modifying effects in females, preventing severe clinical courses including e.g. chronic renal disease. These assumptions remain limited due to the scarce comprehensive data about p.N139S available in literature, discussing this respectively novel mutation being of pathogenic impact [17]. However, long-term results remain to be evaluated in order to judge on clinical severity and outcome over time.

Both of the index patient's children are likely to develop organ involvement as seen in their biological relatives. As therapeutic effects of ERT have been reported to be most beneficial when started before organ injury is detectable [21, 22], it is to be discussed whether and when the index patient's children should start receiving
ERT, particularly in the light of the high prevalence of young-aged stroke in the family pedigree.

\section{Conclusion}

In summary, this current case highlights the importance of careful clinical characterization in patients with Fabry disease, who may show additional uncommon constellations and are thus in need of personalized medicine. The impact of potential additional protective effects exceeding the presence of a non-pathogenic GLA allele in female gene carriers require further investigation.

\section{Abbreviations \\ a-Gal A, alpha-galactosidase A; ERT, enzyme replacement therapy; FAZIT, Fabry Center for Interdisciplinary Therapy Würzburg; FD, Fabry disease; GLA, alpha- galactosidase A encoding gene; LV, left ventricle of the heart.}

\section{Acknowledgements}

This work was supported by the Bundesministerium für Bildung und Forschung of the Federal Republic of Germany (BMBF 01EO1504 MO2 to Peter Nordbeck and Christoph Wanner). We thank Mrs. Irina Turkin for her long-standing dedicated work at FAZIT.

\section{Authors' contributions}

Conception and design: DO, PN; analysis and interpretation of data: DO, DV, GE, CW, PN; drafting the article: DO, PN; revising the article: DO, DV, GE, CW, PN. All authors read and approved the final manuscript.

\section{Competing interests \\ Potential conflicts of interest: DO received travel assistance from Genzyme Corporation, Cambridge, Massachusetts, and Shire PIc., Dublin, Ireland. DV received travel assistance from Genzyme Corporation, Cambridge, Massachusetts, and Shire PIc., Dublin, Ireland. GE reports no competing interest. CW received travel assistance, speaker's/advisory board honoraria, and research support from Genzyme and Shire. PN received travel assistance, speaker's/advisory board honoraria, and research support from Genzyme and Shire.}

\section{Consent for publication}

Written informed consent was obtained from the patient for publication of this case report and any accompanying images. A copy of the written consent is available.

Ethics approval and consent to participate

The investigations were approved by the local ethics committee of the University Hospital Würzburg, Bavaria, Germany.

Received: 19 January 2016 Accepted: 15 June 2016

Published online: 19 July 2016

\section{References}

1. http://fabry-database.org.

2. Desnick RJ, Brady R, Barranger J, Collins AJ, Germain DP, Goldman M, Grabowski G, Packman S, Wilcox WR. Fabry disease, an under-recognized multisystemic disorder: expert recommendations for diagnosis, management, and enzyme replacement therapy. Ann Intern Med. 2003;138(4):338-46.

3. Froissart R, Guffon N, Vanier MT, Desnick RJ, Maire I. Fabry disease: D313Y is an alpha-galactosidase $A$ sequence variant that causes pseudodeficient activity in plasma. Mol Genet Metab. 2003;80(3):307-14

4. Germain DP. Fabry disease. Orphanet J Rare Dis. 2010;5:30.

5. Lin HY, Chong KW, Hsu JH, Yu HC, Shih CC, Huang CH, Lin SJ, Chen CH, Chiang $\mathrm{CC}, \mathrm{Ho} \mathrm{HJ}$, et al. High incidence of the cardiac variant of Fabry disease revealed by newborn screening in the Taiwan Chinese population. Circ Cardiovasc Genet. 2009;2(5):450-6.

6. van der Tol L, Smid BE, Poorthuis BJ, Biegstraaten M, Deprez RH, Linthorst GE, Hollak CE. A systematic review on screening for Fabry disease: 
prevalence of individuals with genetic variants of unknown significance. J Med Genet. 2014;51(1):1-9.

7. Morey C, Avner P. Genetics and epigenetics of the X chromosome. Ann N Y Acad Sci. 2010;1214:E18-33.

8. Elstein D, Schachamorov E, Beeri R, Altarescu G. X-inactivation in Fabry disease. Gene. 2012;505(2):266-8.

9. MacDermot KD, Holmes A, Miners AH. Anderson-Fabry disease: clinical manifestations and impact of disease in a cohort of 60 obligate carrier females. J Med Genet. 2001;38(11):769-75.

10. MacDermot KD, Holmes A, Miners AH. Anderson-Fabry disease: clinical manifestations and impact of disease in a cohort of 98 hemizygous males. J Med Genet. 2001;38(11):750-60.

11. Dobrovolny R, Dvorakova L, Ledvinova J, Magage S, Bultas J, Lubanda JC, Elleder M, Karetova D, Pavlikova M, Hrebicek M. Relationship between Xinactivation and clinical involvement in Fabry heterozygotes. Eleven novel mutations in the alpha-galactosidase A gene in the Czech and Slovak population. J Mol Med. 2005;83(8):647-54.

12. Maier EM, Osterrieder S, Whybra C, Ries M, Gal A, Beck M, Roscher AA, Muntau AC. Disease manifestations and $\mathrm{X}$ inactivation in heterozygous females with Fabry disease. Acta Paediatr. 2006;95(451):30-8.

13. Lang RM, Badano LP, Mor-Avi V, Afilalo J, Armstrong A, Ernande L, Flachskampf FA, Foster E, Goldstein SA, Kuznetsova T, et al. Recommendations for cardiac chamber quantification by echocardiography in adults: an update from the American Society of Echocardiography and the European Association of Cardiovascular Imaging. Eur Heart J cardiovasc Imaging. 2015;16(3):233-70.

14. Kramer J, Niemann M, Liu D, Hu K, Machann W, Beer M, Wanner C, Ertl G, Weidemann F. Two-dimensional speckle tracking as a non-invasive tool for identification of myocardial fibrosis in Fabry disease. Eur Heart J. 2013;34(21):1587-96.

15. Weidemann F, Ertl G, Wanner C, Kramer J. The Fabry cardiomyopathy diagnostic approach and current treatment. Curr Pharm Des. 2015;21 (4):473-8.

16. Davies JP, Eng CM, Hill JA, Malcolm S, MacDermot K, Winchester B, Desnick RJ. Fabry disease: fourteen alpha-galactosidase A mutations in unrelated families from the United Kingdom and other European countries. Eur I Hum Genet. 1996;4(4):219-24.

17. Havndrup O, Christiansen M, Stoevring B, Jensen M, Hoffman-Bang J, Andersen PS, Hasholt L, Norremolle A, Feldt-Rasmussen U, Kober L et al. Fabry disease mimicking hypertrophic cardiomyopathy: genetic screening needed for establishing the diagnosis in women. Eur J Heart Fail. 2010;12(6): $535-40$

18. Linhart A, Kampmann C, Zamorano JL, Sunder-Plassmann G, Beck M, Mehta A, Elliott PM, European FOSI. Cardiac manifestations of Anderson-Fabry disease: results from the international Fabry outcome survey. Eur Heart J. 2007:28(10):1228-35.

19. Rodriguez-Mari A, Coll MJ, Chabas A. Molecular analysis in Fabry disease in Spain: fifteen novel GLA mutations and identification of a homozygous female. Hum Mutat. 2003;22(3):258.

20. Ferreira S, Ortiz A, Germain DP, Viana-Baptista M, Caldeira-Gomes A, Camprecios M, Fenollar-Cortes M, Gallegos-Villalobos A, Garcia D, GarciaRobles JA, et al. The alpha-galactosidase A p.Arg118Cys variant does not cause a Fabry disease phenotype: data from individual patients and family studies. Mol Genet Metab. 2015;114(2):248-58.

21. Germain DP, Charrow J, Desnick RJ, Guffon N, Kempf J, Lachmann RH, Lemay R, Linthorst GE, Packman S, Scott CR, et al. Ten-year outcome of enzyme replacement therapy with agalsidase beta in patients with Fabry disease. J Med Genet. 2015;52(5):353-8.

22. Weidemann F, Niemann M, Breunig F, Herrmann S, Beer M, Stork S, Voelker W, Ertl G, Wanner C, Strotmann J. Long-term effects of enzyme replacement therapy on fabry cardiomyopathy: evidence for a better outcome with early treatment. Circulation. 2009;119(4):524-9.

\section{Submit your next manuscript to BioMed Central and we will help you at every step:}

- We accept pre-submission inquiries

- Our selector tool helps you to find the most relevant journal

- We provide round the clock customer support

- Convenient online submission

- Thorough peer review

- Inclusion in PubMed and all major indexing services

- Maximum visibility for your research

Submit your manuscript at www.biomedcentral.com/submit
C Biomed Central 